\title{
As mudanças das competências diante da transformação das organizações
}

\section{The changing competencies in the face of organizations' transformation}

DOI: $10.46814 /$ lajdv3n5-032

Recebimento dos originais: 01/05/2021

Aceitação para publicação: 31/06/2021

\section{Ana Cristina Brandão Ribeiro Silva}

Mestre em Gestão do Conhecimento e Tecnologia da Informação, Mestre em Ciências da Educação. Coordenadora de Curso e Docente da Faculdade Horizonte

E-mail: anacbrs@yahoo.com.br

\section{RESUMO}

Este artigo apresenta discussão sobre as competências (conhecimentos, habilidades e atitudes) desenvolvidas na formação dos bacharéis secretários executivos, egressos da academia, considerando que as mudanças nas organizações exigem aplicação imediata das respectivas dimensões das competências, no sentido de torná-los aptos a atuarem e preencherem as vagas de trabalho existentes conforme o perfil de atuação: assessor, gestor, consultor e empreendedor, indicado pelas diretrizes curriculares nacionais, e consequentemente exigido pelo mercado de trabalho. A formação acadêmica é parte obrigatória para as comprovações profissionais, porém, somente com a sintonia das competências será agregado valor à organização diante do comprometimento com as responsabilidades impostas pelo cargo ou função, prevalecendo assim o conhecimento como base do aprendizado recebido durante o curso, as habilidades como as práticas aplicadas em determinadas situações e contexto, as atitudes como ações empregadas. O estudo aponta que o curso de nível superior busca formar os acadêmicos no intuito de atender ao exigido pelo Ministério da Educação, contudo, observase lacunas sobre a aplicação das competências no mercado de trabalho que precisam ser preenchidas conforme as exigências mercadológicas.

Palavras-chave: Competência. Formação. Mercado de trabalho. Secretariado.

\begin{abstract}
This article presents a discussion about the competencies (knowledge, skills and attitudes) developed in the formation of bachelors executive secretaries, graduates of the academy, considering that the changes in organizations require immediate application of the respective dimensions of competencies, in order to make them able to act and fill the existing job vacancies according to the performance profile: advisor, manager, consultant and entrepreneur, indicated by the national curriculum guidelines, and consequently required by the labor market. The academic training is a mandatory part for professional evidence, however, only with the tuning of the competencies will value be added to the organization before the commitment to the responsibilities imposed by the position or function, thus prevailing the knowledge as the basis of learning received during the course, the skills as the practices applied in certain situations and context, the attitudes as actions employed. The study points out that the higher education course seeks to train the academics in order to meet the requirements of the Ministry of Education, however, there are gaps about the application of skills in the labor market that need to be filled according to market demands.
\end{abstract}

Key words: Competence. Training. Labor market. Secretarial. 


\section{INTRODUÇÃO}

As mudanças oriundas da globalização promoveram uma evolução científica e tecnológica que modificaram a dinâmica das organizações impondo uma nova postura do profissional ante ao mercado de trabalho. Este novo cenário alterou sobremaneira todas as competências profissionais, principalmente as do secretariado executivo, originando um processo de transformação.

Neste panorama, destaca-se que o capital humano é a expressão viva para o alcance dos resultados organizacionais, no qual o secretário executivo tem uma participação efetiva por meio de uma história de conquistas, tais como: regulamentação da profissão, formação superior, código de ética, registro profissional, organização sindical, a luta pela criação do conselho nacional de secretariado, inserção como área do conhecimento, que permitiram oportunidades no âmbito científico e mercadológico. Entretanto, observa-se uma lacuna entre a formação acadêmica, as mudanças, as exigências e o reconhecimento do mercado de trabalho. Talvez em consequência do modelo de formação promovido pelas Instituições de Ensino Superior (IES), e/ou pela miopia das organizações sobre a capacidade profissional dessa categoria, ou ainda pela falta de empoderamento do próprio profissional e pelas mudanças nas competências diante do contexto do trabalho.

Enquanto, a quebra de barreiras econômicas, financeiras, a transformação do mercado de trabalho, a velocidade da comunicação, a evolução tecnológica, bem como as conquistas profissionais alcançadas permitiram um espaço nas dimensões do trabalho do secretário. Por outro lado, torna-se necessário repensar alguns aspectos, tais como, as profissões são permanentes, porém, seguem uma evolução, e as competências são dinamizadas em face das transformações, sociais, financeiras, econômicas, políticas e tecnológicas (ASHER, 2008; FLEURY e FLEURY, 2001).

Deste modo, é imprescindível ao secretário compreender como aplicar as suas competências no atual mercado de trabalho, pois, só os critérios formais de qualificação não irão garantir sua estabilidade. Nesta direção, Asher (2008) confirma que é primordial ao profissional, antecipadamente, ter as competências requeridas. Antes de assumir uma vaga de trabalho precisa estar preparado para tal, considerando que o seu diferencial será pautado sobre esse aspecto. O diploma especificamente não possibilitará diferencial sem ser somado às competências desenvolvidas e praticadas no decorrer da vida pessoal, profissional e acadêmica. É preciso ter domínio, capacidade de ação e antecipar-se aos acontecimentos.

Nesta percepção, cabe destacar que as atividades inerentes aos secretários às vezes são exercidas por outros profissionais, principalmente em empresas públicas, que geralmente são realizadas por funcionários de carreira ou cargos de confiança. Por outro lado, nas empresas privadas são desenvolvidas por outras categorias, dificultando a inserção, valorização e reconhecimento da referida profissão de secretariado. Contudo, destaca-se que as evoluções geraram mudanças de todas 
as ordens e, consequentemente, as funções ganharam novas formas e métodos, se expandido em diversas áreas do conhecimento com a caracterização de multidisciplinaridade, polivalência, e adaptação ao contexto de atuação.

Com isso, constata-se que o mundo moderno apresenta diversos fatores que induzem o mercado de trabalho a exigir do profissional à aplicação das suas competências em diversos campos do saber: intelectual, tecnológico, cognitivo, técnico, relacional, entre outros. Neste cenário, a conectividade, flexibilidade, autonomia e o dinamismo são demandados pelas organizações que passam por contínuas mudanças, que além dos cargos e funções não serem permanentes, estão se reduzindo. Na realidade, atualmente, expande-se o grau de complexidade do trabalho, exigindo de o profissional alto nível de desempenho. Consequentemente, as exigências das qualificações e das experiências são extensas e mais complexas.

Diante disso, os profissionais precisam refletir como quebrar seus paradigmas, considerando que os métodos utilizados habitualmente não servirão para todas as situações vivenciadas. As formas de trabalho não podem ser em uma só direção, precisam ser flexíveis visando acompanhar as demandas contemporâneas, para ter condições de ultrapassar os momentos de imprecisão. Em meio a esse panorama, é preciso refletir se as ações empregadas estão adequadas a esse novo cenário. Mais do que isso: entender a relevância do seu papel no contexto organizacional, a depender do perfil em que está inserindo na organização, como assessor, gestor, consultor, empreendedor.

Dito isso, destaca-se que as formas de trabalho são instáveis, modificam-se constantemente. Nesta perspectiva, o profissional deve ser um fornecedor das suas competências que agregam valor à organização, analisando o contexto do ambiente e dos negócios com foco nos objetivos da empresa em que atua, com atitudes eficazes. Além disso, deve verificar quais atividades são mais complexas para desenvolver suas competências, de tal modo a convencer sua organização sobre sua capacidade de desempenho.

Todavia, a compreensão sobre a incerteza do futuro é imprescindível, pois, as possibilidades de falhas, erros, acertos e oportunidades são diversas, e as competências encontram-se no centro desse cenário de instabilidade. Portanto, a visão ampliada e a estratégia continuam sendo fundamentais diante desse panorama de alterações, mas não é o suficiente. As transformações ocorrem em todos os setores do mercado aceleradamente, e de certo modo prejudica a compreensão e acompanhamento de todo processo.

Sendo assim, caso o profissional não tenha capacidade de inovação e vontade de atuar no ritmo necessário com visão prévia dos problemas, em busca dos resultados para a organização, tenderá a ficar deslocado na empresa e no mercado de trabalho. Essa concepção confirma-se tendo em vista que a transformação é uma condição sine qua non das empresas e dos indivíduos. 
No passado algumas empresas resistiram à ideia de inovar devido a perspectiva que eram líderes de mercado, contudo, desapareceram. Diante disso, compreende-se que o domínio mercadológico, anteriormente, ficava nas mãos de poucas empresas, porém, no atual cenário dos negócios o desenho é bem diferente. A competitividade é acirrada, e depende de ações efetivas para as organizações se estabelecer e continuar na rota do desenvolvimento e da evolução.

O mundo tecnológico e globalizado promove diversas oportunidades, mas ao mesmo tempo modifica completamente as regras do "jogo" para o qual as empresas e os profissionais estavam preparados. Por isso, quem não ousar poderá trilhar a rota das empresas que não perceberam a necessidade de se transformar e inovar seus modelos de gestão, competências, procedimentos e ações.

\section{O PERFIL DO SECRETÁrio EXECUTIVO, FORMAÇÃo E O MERCAdo DE} TRABALHO

As organizações demandam profissionais qualificados e preparados com a capacidade de inovação e pensamento sistêmico com amplitude e diversidade de conhecimentos em diversas áreas, além dos adquiridos na sua formação, principalmente no que diz respeito aos processos de análise e aprendizagem.

Segundo Silva (2007) com a abertura e integração de mercado foi ampliada a competitividade impondo às organizações que pretendiam permanecer líderes de serviços e produtos, a um aprimoramento de seus processos estratégicos de gestão visando aumentar o seu nível de qualidade com a contratação de profissionais competentes. Nesta perspectiva, os padrões profissionais elevaramse e o secretário executivo necessariamente precisou reformular seu papel e perfil no processo de mudanças.

Nesta perspectiva, o profissional precisa identificar suas competências em relação a sua atuação, principalmente, se estão conectadas à estratégia da empresa, e que contribuam com o alcance da missão, objetivos e metas organizacionais. Diante disso, demonstra-se a seguir, o perfil do secretário relativo as funções de assessor, gestor, empreendedor e consultor, de tal modo que possa aplicar suas competências conforme o contexto do trabalho, e por sua vez colaborar com os resultados esperados pela organização.

\subsection{QUADRO DEMONSTRATIVO DO PERFIL DO SECRETÁRIO EXECUTIVO}

\begin{tabular}{|c|c|c|c|}
\hline ASSESSOR & GESTOR & EMPREENDEDOR & CONSULTOR \\
\hline $\begin{array}{lr}\text { Subsidiar e } & \text { apoiar o } \\
\text { executivo } & \text { com } \\
\text { conhecimento } & \text { técnico }\end{array}$ & $\begin{array}{l}\text { Supervisionar equipes, } \\
\text { gerenciar processos, indicar } \\
\text { estratégias e ações com }\end{array}$ & $\begin{array}{l}\text { Inovar os processos, } \\
\text { procedimentos } \\
\text { ações }\end{array}$ & $\begin{array}{l}\text { Propor alternativas que } \\
\text { possam mitigar ou } \\
\text { solucionar problemas }\end{array}$ \\
\hline
\end{tabular}




\begin{tabular}{|c|c|c|c|}
\hline $\begin{array}{l}\text { para as tomadas de } \\
\text { decisão e ações } \\
\text { estratégicas. }\end{array}$ & $\begin{array}{l}\text { habilidades em funções } \\
\text { administrativas e cognitivas. }\end{array}$ & $\begin{array}{l}\text { organização com } \\
\text { base em } \\
\text { conhecimentos } \\
\text { explícitos e tácitos, } \\
\text { habilidades } \\
\text { criativas, } \\
\text { administrativas, } \\
\text { tecnológicas } \\
\text { digitais. }\end{array}$ & $\begin{array}{l}\text { com alto nível de } \\
\text { complexidade baseado } \\
\text { em conhecimentos } \\
\text { técnicos, métodos de } \\
\text { gestão e soluções } \\
\text { tecnológicas. }\end{array}$ \\
\hline
\end{tabular}

Fonte: autoria própria

O perfil apresentado no quadro 2.1, não se trata de uma mera tendência, e sim da interpretação da Resolução no 3/2005, do MEC/CNE - Conselho Nacional da Educação, publicado no D.O.U de 27/6/2005 (BRASIL, 2005, Seção 1, p. 79). Então, a partir da referida análise, constata-se que a atuação do secretário executivo se encontra ancorada nos níveis tático e estratégico das organizações, bem como na sua formação acadêmica, nas suas competências técnicas e individuais.

Fica evidente pela legislação estabelecida que o secretário executivo deve ser registrado nos órgãos competentes para exercer a profissão. Contudo, independente disso, deve demonstrar a capacidade de análise, interpretação e articulação de conceitos às realidades inerentes à administração pública, privada ou terceiro setor, nos níveis micro, meso e macro organizacional.

Por outro lado, o profissional para atuar nesses níveis precisa de competências indispensáveis, tais como, conhecimento, habilidade e atitude (CHA), as quais Silva (2010) caracteriza como trinômio das competências. O ponto principal deste conjunto de dimensões é a sua abrangência considerando a valorização do indivíduo conforme suas competências com abordagem complexas. Silva (2009, p.177) cita que "as competências requeridas ao perfil adequado às novas transformações não se resume apenas a instruções prescritas, mas a diversas competências e ações que superem as expectativas organizacionais." A competência visa atingir o desempenho superior no cargo que ocupa. (BOYATZIS, 1982; McCLELLAND, 1973; SPENCER e SPENCER, 1993). Trata-se do alinhamento da aprendizagem do indivíduo com as necessidades organizacionais, indicando aspectos que transcendem a qualificação. (ZARIFIAN, 2001; LE BOTERF, 2003).

Daí a necessidade da compreensão do secretário sobre sua relação com a empresa e o seu contexto de atuação. Nesse sentido, discute-se as dimensões das competências considerando que o indivíduo perpassa por diferentes situações as quais precisa se adaptar, e por vezes redesenhar e atualizar suas competências, compreendendo que o conhecimento indica o saber que o indivíduo categorizou por meio de leituras, teorias, ideias, experiências, que foram internalizados, registrados, absorvidos, e geralmente dependem do entorno para prover resultados.

Por sua vez, a habilidade trata-se do desenvolvimento e aplicação do conhecimento por meio da capacidade de exteriorizar o que está registrado e acumulado na memória do indivíduo, 
considerando os papéis sociais que vivencia em outros ambientes externos à organização, e que o influencia em suas ações. Por outro lado, a dimensão atitude é o querer fazer e acontecer, permeada de vínculos sociais e emocionais que impactam o comportamento do indivíduo em relação aos demais colegas de trabalho ou situações, e com isso impulsiona a efetividade da habilidade.

Nesta percepção, Fleury e Fleury (2001), destacam sobre a necessidade da ação e da mobilização para a competência existir bem como enfatizar sua complexidade. Nesta mesma direção Zabala e Arnau (2010), indicam que a competência só ocorre efetivamente quando o saber, saberfazer e saber-ser se encontram. Em complemento as percepções dos respectivos autores, apresenta-se a seguinte equação: conhecimento + habilidade + atitude + entorno + valores = ação efetiva. Para tanto esse resultado depende da participação/somatória de todas as dimensões para consolidar e efetivar o resultado esperado pela organização.

Além desse trinômio de competências, Mussak (2010) acrescenta dois termos importantes, entorno e valor, os quais somados ao trinômio caracterizado por Silva (2010) como polinômio das competências, que resulta nos conhecimentos, habilidades, atitudes, valores e entorno. Nesta proposição, infere-se que os valores direcionam nossas competências para os princípios e pressupostos, fazendo uma grande diferença, principalmente, em nossas atitudes. Por outro lado, cabe destacar que o entorno não depende especificamente do indivíduo, contudo, são meios e condições necessários, tais como ambiente, instrumentos, equipamentos, para o ciclo das competências se consolidarem plenamente. Dessa forma, apresenta-se a seguinte equação: conhecimento + habilidade + atitude + entorno + valores = ação efetiva e plena, na qual vislumbra-se a integração de todas as competências para a efetividade plena das ações.

Neste contexto, reitera-se que o bom desempenho profissional se compõe da sincronização das competências. Deste modo, exemplifica-se, que se a empresa exige um atendimento ao cliente com qualidade, é necessário que o profissional conheça os serviços, as rotinas, procedimentos, processos, instrumentos de trabalho. Assim sendo, é preciso saber o que está falando, ter a habilidade de comunicar-se com atitude positiva para manifestar-se com segurança e receptividade, ter domínio das ferramentas tecnológicas, bem como querer atender com eficácia e eficiência. Em suma, percebe-se no exemplo dado, a presença de cada dimensão, pois, caso ocorra a ausência de uma delas nesta atividade, o serviço possivelmente não será prestado satisfatoriamente.

Pondera-se que diante do atual contexto mundial, a alta administração da empresa precisa tomar decisões complexas permeadas das mais variadas mudanças, as quais exigem a participação de capitais intelectuais preparados para lidar com tal realidade, e que saibam utilizar o seu potencial baseado em soluções. A inovação pode ser uma vantagem considerando que as empresas buscam competências 
vinculadas à criatividade para solucionar problemas complexos e se desenvolver no mercado mais rápido que os seus concorrentes.

Nesta esteira, cita-se Mussak (2010) o qual acredita que além das competências existe a metacompetência, "[...] a entrega mais do que se espera", no qual explica ser o encontro das competências técnicas, práticas, éticas e estéticas. Assim, infere-se que a metacompetência seja o adicional de combinação para o capital humano implantar e propiciar ações que asseguram às empresas um retorno sobre o investimento realizado.

Desta forma, compreende-se a importância da caracterização da metacompetência na visão de Mussak (2010) a qual esclarece o benefício dessa combinação estreita em diferentes níveis das dimensões das competências alinhadas com as necessidades da organização.

Desta maneira, apresenta-se a seguir a caracterização da Metacompetência com base em Mussak (2010) no quadro 2.2, a seguir.

\subsection{DEMONSTRATIVO DA METACOMPETÊNCIA}

\begin{tabular}{|l|l|}
\hline \multicolumn{1}{|c|}{ Competências } & \multicolumn{1}{c|}{ Caracterização } \\
\hline Técnicas & $\begin{array}{l}\text { Competências desenvolvidas nas instituições de ensino e treinamento. } \\
\text { Nestas competências, é indicada a necessidade de o profissional ter capacidade e } \\
\text { habilitação com permanente processo de aperfeiçoamento. }\end{array}$ \\
\hline Práticas & $\begin{array}{l}\text { O conhecimento e as suas aplicações da gestão estão inseridos nesta competência, } \\
\text { que por sua vez externalizam as competências técnicas. }\end{array}$ \\
\hline Éticas & $\begin{array}{l}\text { Considera-se as competências das relações interpessoais, humanas, com atenção } \\
\text { às normas de convivência, conduta, os preceitos morais, o respeito ao semelhante } \\
\text { e a diversidade entre as pessoas e ao meio ambiente. Indica que estão além da } \\
\text { conduta ética, tratando todos com respeito, bem como ter cuidado com o próximo. }\end{array}$ \\
\hline Estéticas & $\begin{array}{l}\text { Aspectos que facilitam a harmonia do ambiente, as relações sólidas, belas e } \\
\text { harmônicas integram este tipo de competência. Compreende a preocupação com } \\
\text { a harmonia do ambiente. A boa comunicação interpessoal, bom diálogo com a } \\
\text { harmonia e o uso coerente de frases e palavras. }\end{array}$ \\
\hline
\end{tabular}
Fonte: Adaptado de Mussak (2010)

A metacompetência indicada por Mussak (2010) apresenta nas entrelinhas o polinômio citado por Silva (2010), no qual encontra-se caraterizado, o conhecimento técnico, conhecimento prático, respeito ao próximo e ao ambiente de trabalho, as relações interpessoais, entre outros das dimensões das competências. Na visão de Silva (2009) as organizações se preocupam em treinar e desenvolver as competências de seus funcionários. Daí a importância de distinguir essas dimensões no qual pode-se enfatizar as duas vias do conhecimento, explícito e tácito que segundo Nonaka; Takeuchi (1997), para se tornar uma "empresa que gera conhecimento" a organização deve completar uma "espiral do conhecimento". 
A partir dessa percepção, a espiral que circula do tácito para tácito, de explícito a explícito, de tácito a explícito, e finalmente, de explícito a tácito, indicado por Nonaka; Takeuchi (1997), demonstra que o conhecimento deve ser internalizado, mas também exteriorizado, socializado e combinado para tornar-se parte do conhecimento de cada pessoa. Após, a conclusão desse processo, a espiral retoma o seu ciclo com níveis cada vez mais elevados, ampliando e efetivando a aplicação do conhecimento e promovendo diferencial e poder ao capital intelectual necessário e exigido pela empresa.

Isso posto, torna-se nítida a importância desses tipos de conhecimentos para as empresas que pretendem inovar, expandir e se integrar em novas redes de conexão com visão para o progresso tecnológico. Os novos modelos de gestão impulsionam as empresas a exigir cada vez mais dos profissionais a repensar sobre sua capacidade, suas competências, principalmente, referente ao conhecimento tácito e explícito, de tal modo que possam contribuir para o aumentar a competividade e melhoria dos resultados da organização.

Assim, enfatiza-se que não basta ter criatividade e boas ideias, é preciso compartilhar, transformar, aplicar. Nessa visão, observa-se que o secretário executivo faz parte desse contexto como agente de mudança e inovação, apoiando o processo de tomada de decisões, prevendo acontecimentos e ações, incrementando a qualidade dos serviços, processando e incrementando o compartilhamento da informação, bem como disseminando e administrando o aprendizado para aumentar a competitividade e melhoria da performance organizacional.

\section{ATUAÇÃO DO SECRETARIADO EXECUTIVO: ASSESSOR, GESTOR, CONSULTOR, EMPREENDEDOR}

O autoconhecimento do secretariado é primordial para a atuação nas organizações, assim, como para atender ao perfil desejado pelo mercado de trabalho. Desta forma, precisa saber fazer diagnóstico estratégico da organização, análise interna e externa, saber se a missão está alinhada com o negócio da empresa, entender as projeções fundamentadas nos cenários para colaborar na decisão. Além disso, estar realmente qualificado para estabelecer objetivos e metas, e a partir do contexto entregar à organização o que ela realmente necessita e que produza resultados.

Na posição como consultor, o secretário deve ser estrategista, analisar os problemas de forma sistêmica considerando as variáveis existentes na organização, as causas e seus efeitos, entendendo as relações e, a partir dos dados e informações obtidos, propor ações gerenciais. Deve ainda, verificar as falhas existentes, ter perspicácia e segurança, entender a linguagem das pessoas, utilizar recursos técnicos adequados com capacidade naquilo que está analisando. Além disso, precisa focar no 
desenvolvimento de ações que possam propiciar soluções adequadas, e principalmente com argumentos e fundamentação técnicos.

Como assessor deve ser reflexivo, propor caminhos, indicar as justificativas e a melhor solução. Estabelecer apoio aos núcleos estratégicos e decisórios, como também, conectar-se com as realidades, as competências, os indivíduos, os staffs, os níveis hierárquicos. Desse modo, Medeiros e Hernandes (1999) destacam que o secretário assessora o executivo com a indicação de soluções efetivas, exercendo um papel de destaque na organização, seja no âmbito social, organizacional, administrativo. Além de intermediar os momentos de conflitos e subsidiar na tomada de decisão. Diante disso, destacase a importância da atuação desse profissional em setores estratégicos da organização.

No papel de gestor tem autonomia, delibera em relação as estratégias adequadas, identificando e administrando dados e informações, gerenciando conhecimentos e desenvolvendo planos para atingir os objetivos propostos. Ainda, produz estruturas e fornece subsídios ao nível estratégico para definir políticas e procedimentos pertinentes ao planejamento. Por fim, fornece assessoria na implementação dos planos sem ultrapassar limites hierárquicos com decisões fundamentadas na escolha de dados e informações relevantes. Por essa via, contribui significativamente para o bom desenvolvimento e satisfação dos interesses e necessidades do seu grupo e da organização.

$\mathrm{Na}$ perspectiva do perfil empreendedor, encontra-se as competências relativas à inovação, criatividade, visão para novas oportunidades. Com isso, compreende-se que esse perfil proporciona às iniciativas exigidas pelas organizações devido o atual mundo contemporâneo, com transformações de toda natureza. Essa afirmação vem ao encontro do entendimento de Seiffert (2008) em que o empreendedor se posiciona em duas perspectivas, inovação com criação de novos negócios e desenvolvimento, ressaltando a necessidade de ações que possam alavancar os objetivos da organização. Desta forma, o empreendedor age como inovador aplicando novos métodos, ferramentas e estratégias aos objetivos principais da organização.

Os perfis discutidos acima exigem uma análise do contexto de atuação para aplicação das competências técnicas e individuais, no qual o profissional precisa ter técnica, iniciativa, boa conectividade humana, habilidades políticas, liderança e negociação com as pessoas do ambiente. São habilidades e atitudes características do secretário que conhece suas empresas, e colaboram para minimizar conflitos buscando proporcionar um ambiente agradável aos stakeholders. Milkovich e Boudreau (2000) confirmam essa premissa afirmando que as relações devem propiciar harmonia entre os indivíduos. Compreende-se que desta maneira se facilita as ações e estratégias institucionais.

Obviamente, o cenário atual exige de o secretário atender as expectativas de trabalho não só da unidade que desenvolve suas atividades ou dos executivos, mas, também, de todas a organização. Com base nessa premissa, o profissional passou a ser agente estratégico de mudanças, gestor de informações, 
consultor com ações e soluções inovadoras, empreendedor com visão ampliada antecipando-se às mudanças, por meio de seus conhecimentos, habilidades e atitudes adquiridos e desenvolvidos no decorrer da formação profissional e acadêmica. Assim, o desenvolvimento e o aprendizado das competências que o cargo exige tornaram-se essenciais ao bom desempenho do trabalho propiciando um ponto de referência à formação contínua desses níveis de aprendizado e ensino.

Na visão de Medeiros e Hernandes (1999) as competências secretariais compreendem atividades objetivando oferecer maior qualidade dos produtos ou serviços da empresa para a qual trabalha, indicando a necessidade de o profissional ser globalizado, com visão sistêmica, integral, polivalente e ao mesmo tempo técnica. Por outro lado, Demo (1999, p.259) afirma que a inserção das profissões nas organizações depende das competências “educativas e científicas”, pois além de produzir os aspectos necessários para formação desse acadêmico, interfere sobremaneira na "produtividade econômica".

Neste viés, destaca-se o parecer CES/CEN 102/2004 do Ministério da Educação e Conselho Nacional da Educação, o qual indica a utilização das Diretrizes Curriculares Nacionais de forma dinâmica “(...) que atenda aos diferentes perfis de desempenho a cada momento exigidos pela sociedade, nessa 'heterogeneidade das mudanças sociais' sempre acompanhadas de novas e mais sofisticadas tecnologias (...) " (BRASIL, 2004, p.2), demandando uma contínua revisão do projeto pedagógico do curso visando inserir no mercado de trabalho, profissionais qualificados e adaptados às constantes mudanças ocorridas pela era da globalização. Essa atualização e acompanhamento, é importante para preparar os egressos recém-chegados ao universo do trabalho.

Diante disso, pontua-se a seguinte consideração em relação às atividades descritas na Lei n. ${ }^{\circ}$ 7.377, de 30/09/85, alterada pela Lei 9261, (BRASIL, 1985, 1996), as atribuições estão demarcadas de forma generalizada, porém, deve-se observar o segmento da empresa e consequentemente o conhecimento específico demandado, bem como quais as competências devem ser aplicadas visando facilitar a inserção e promover o diferencial do profissional no mercado de trabalho. A atuação do egresso da IES, não deve se basear somente na formação de bacharel graduado na área. A capacidade de inovação, criação, adaptação social e profissional, assimilação, análise, reflexão e conectividade tecnológica e humana devem ser elementos presentes nas ações profissionais.

Dada a afirmação de Pires de Carvalho e Grisson (2001), que no decorrer da vida, modificamos ou transformamos atitudes conforme o cenário vivenciado e as sinalizações recebidas, tais como: hábitos, comportamentos e situações, enfatiza-se que todas as alterações exige um modelo de educação básica centrada na formação qualitativa não só com transferências de conhecimentos, mas, fomentando o confronto, renovação, criatividade, ou seja, a diretriz curricular não pode ser imposta como um 
"pacote fechado" deve ir além. (DEMO, 1999, p. 101). Para o autor as disciplinas dos cursos são a princípio contemporâneas apresentando as áreas mais requisitadas para o mercado.

Assim, quando Demo (1999, p.101), apresenta o termo "aprender a aprender", significa que os conhecimentos recebidos, transmitidos necessitam de estratégias que propiciem ao acadêmico ferramentas, recursos e visão da realidade “[...] enfrentar novos desafios, refazer conhecimento", promovendo uma percepção moderna de ensino com nova roupagem, mais criativo, moderno e autônomo.

Nessa perspectiva, os acadêmicos transformam-se em partes integrantes do projeto de ensino, com participação e posicionamento efetivos, compartilhando ideias, e consequentemente, produzindo o conhecimento. $\mathrm{O}$ autor, acrescenta que o docente dispensa a autoridade formal para ser um “(...) formulador, organizador, revisor e atualizador dos conteúdos a serem socializados” (p.101)

\subsection{DEMANDAS DO MERCADO DE TRABALHO}

Toda profissão requer uma diretriz, e um dos objetivos principais dos profissionais, é aplicar imediatamente os conhecimentos. Neste contexto, ressalta-se a importância da análise e reflexão de como o mercado de trabalho reage diante dos cenários existentes. Diante disso, como ponto de partida deve-se desenvolver as competências exigidas ao indivíduo para seu devido aproveitamento no ambiente competitivo de trabalho.

De acordo com Dutra (2004) somente a qualificação para desenvolver o trabalho não certifica que o profissional vai exercer a contento o cargo ou função demandado. Assim, Martins (2006) enfatiza que apesar das IES discutirem sobre as exigências para o curso de Secretariado Executivo em relação as mudanças da matriz curricular, não é suficiente para preencher as lacunas das competências profissionais existentes. Entretanto, o projeto pedagógico do curso deve acompanhar as demandas do mercado visando a qualidade necessária para a formação do egresso. Dessa forma os coordenadores do curso devem estar alinhados aos anseios das organizações além dos padrões estabelecidos pelo órgão regulador de ensino, pois, as empresas trabalham alinhadas as novas tendências, redefinindo os cargos e as tarefas conforme as exigências impostas pela globalização.

As novas relações de trabalho são guiadas pela capacidade do profissional saber antecipar-se e estar alinhado às mudanças acompanhando as tendências organizacionais (KAUFMANN, 1990). Este pensamento indica que o mercado de trabalho seleciona pessoas com perfil inovador e conhecedora de novos modelos de gestão. As mudanças são constantes, forçando as organizações a repensar suas estruturas para não ficarem fora do contexto real. Zorzi (2001) considera que a atual gestão está direcionada a um ângulo de $360^{\circ}$ graus, e não fracionada. Portanto, essa nova gestão impulsiona um novo delineamento do desempenho do secretariado executivo, forçando-o a uma análise da função, 
sobre às necessidades que o mercado demanda diante das exigências mercadológicas, tais como, as conectividades humanas e tecnológicas, transformação digital, inteligência artificial, dentre outros.

Por outro viés, Meneses e Zerbini (2009, p.5) observam que os esforços físicos e psicomotores que eram exigidos foram substituídos e valorizados por um esforço cognitivo, indicando que os atuais profissionais não são produtos ou recursos, os quais oferecem ou vendem serviços "força de trabalho", e sim, possuem "conhecimentos e habilidades intelectuais", ou por que não dizer capital intelectual. Assim, os autores citam sobre "[...] o domínio de uma série de estratégias de análise no intuito de descrever estas novas tarefas e competências requeridas."

Por outro lado, Pires de Carvalho e Grisson (2001), entendem que as empresas selecionam e recrutam o profissional conforme determinado recurso. Apresentam ainda, que para imediata inserção no mundo do trabalho, e não estagnar, o profissional deve atentar-se ao comportamento do mercado. Em contrapartida Demo (1999) acrescenta que a demanda é por aqueles indivíduos que produzam e compartilhem conhecimentos participando ativamente das decisões organizacionais. Desta Maneira, as IES precisão promover uma matriz curricular adequada às exigências externas, com um portfólio de entrega significativo. Por sua vez, o mercado precisa compreender como utilizar às competências e atribuições desses profissionais.

\section{CONSIDERAÇÕES FINAIS}

Neste artigo buscou-se discutir as lacunas existentes sobre as competências na dimensão acadêmica, questionando o formato do seu desenvolvimento e aplicação visando preparar o egresso para atuar no mercado de trabalho conforme o perfil de assessor, gestor, consultor e empreendedor. Desse modo, compreende-se que o alcance do objetivo principal foi alcançado, tendo em vista que o profissional de Secretariado Executivo que as IES formam e preparam para o mercado de trabalho precisa apresentar capacidade que atenda as expectativas dos executivos e das organizações, dotados de autonomia, conhecimentos, habilidades, atitudes que contribuam com as decisões executivas e organizacionais.

Entretanto, vale destacar que a formação superior (conteúdos básicos, específicos e teóricopráticos), apesar de sua efetiva integralização, é diferente a depender de cada IES, tanto no campo tecnológico, administrativo, idiomas, estágio, dentre outros. Nesta perspectiva, enquanto as exigências do mercado são renovadas aceleradamente, a busca é por profissionais que mobilizam estratégias e raciocínios capazes de transformar processos e ações, adquirindo novas experiências e preparados a enfrentar situações complexas.

Desta forma, a preocupação das IES deve ser permanente em proporcionar os meios necessários para a aplicação de métodos que agilizem a transferência dos conhecimentos, habilidades e atitudes 
aos acadêmicos de tal modo que possam aplicar efetivamente nas suas organizações. As mudanças continuarão nas organizações, assim, a competitividade ficará mais acirrada e as instituições de ensino superior precisam ser rápidas na mutação do ambiente, adaptando-se às novas regras impostas pelo mercado de trabalho, acompanhando e participando conjuntamente deste processo, buscando excelência e dinamismo no ensino proporcionado ao graduando.

Neste cenário, os processos e métodos precisam ser diferenciados e ressignificados, pois, enquanto na era industrial o capital era só a moeda principal, que enriquecia as fábricas, atualmente é o indivíduo que faz a diferença nos resultados. Diante disso, as organizações que pretendem competir não devem investir só em equipamentos e, sim em seus profissionais, integrantes de sua equipe. Assim, esse capital intelectual dotado de capacidade e qualificação será cada vez mais requisitado por propiciar vantagens competitivas, capacidade de mobilizar recursos, capacidade mental de inovar continuamente e proporcionar valor à organização.

Sendo assim, deve ser um profissional conectivo, se posicionando e gerando resultados coletivos, resolvendo problemas, e não só identificando as competências necessárias, mas sintonizando-as. Ser um gerador de resultados concretos, fornece soluções, inovações, conhecer e entender as tecnologias mais adequadas para a organização. Ter visão sistêmica na qual nenhuma ação deve ser empreendida sem considerar o seu impacto em outras áreas da organização e da sociedade. Além disso, possuir um arcabouço conceitual com um conjunto de conhecimentos e ferramentas para esclarecer os padrões e saber como modificá-los efetivamente.

O secretariado executivo se integra no processo de globalização, com isso, a necessidade de desenvolver e aprimorar suas habilidades além dos conhecimentos básicos e específicos exigidos pelo órgão de educação superior deve ser encontrado por meio de um ensino continuado. Desta forma, a matriz curricular do curso deverá ser determinada pela atualização das competências que fazem o diferencial na competitividade de mercado, pois a evolução e renovação é uma referência para o sucesso profissional.

Assim, registra-se, portanto, a recomendação de novos estudos principalmente sobre pesquisas com coordenadores, recrutadores, egressos secretários executivos para discutir e apontar de forma aplicada as competências proporcionadas pelas IES: as que o mercado de trabalho exige, e as competências que os secretários conseguem aplicar no ambiente real do trabalho. Desta maneira, espera-se que este estudo proporcione estímulo a novas pesquisas e debates acerca do referido assunto, visando movimentar e transformar as formas e meios de ensino para propiciar capacidade e domínio aos profissionais. 


\section{REFERÊNCIAS}

ZABALA, Antonio.; ARNAU, Laia. Como aprender e ensinar competências. Porto Alegre: Artmed, 2010

ASHER, Donald. Quem é promovido, quem não é e por quê: gestão estratégica de carreira. Tradução. Ludmila Hashimoro. São Paulo: Editora Gente, 2008.

BOYATZIS, Richard E. The Competent Management: A Model for Effective Performance. Nova York: Wiley\&Sons, 1982.

BRASIL. Lei 7.377, de 30 de setembro de 1985. Dispõe sobre o exercício da profissão de Secretário e dá outras providências. Diário Oficial da União de $1^{\circ}$ de outubro de 1985 . Presidência da República. p.14314. Seção I.

BRASIL. Lei 9261, de 10 de janeiro de 1996. Altera a redação dos Incisos I e II do art. $\mathbf{2}^{\mathbf{o}}$, ocaput do art. $3^{\circ}$, o inciso VI do art. $4^{\circ}$ e o parágrafo único do art. $6^{\circ}$ da Lei $\mathbf{n}^{0} 7.377$, de 30/09/1985, que dispõe sobre o exercício da profissão de secretário. Diário Oficial da União de11 de janeiro de 1996. $\begin{array}{lllllll}\text { Presidência da } & \text { República. } & \mathrm{n}^{\circ} & 8, & \text { p.393. } & \text { Seção } & \mathrm{I} \text {. }\end{array}$

BRASIL. Parecer n. ${ }^{\circ}$ 0102/2004, de 11 de março de 2021. Ministro de Estado da Educação, homologa o Parecer $n^{\circ}$. 0102/2004, de 11 de março de 2004, da Câmara Superior do Conselho Nacional de Educação, que aprova o projeto de resolução que institui as Diretrizes Curriculares nacionais do curso de graduação em Secretariado Executivo, Diário Oficial da União de 12 de abril

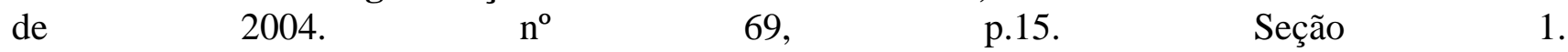

BRASIL. CNE. Conselho Nacional de Educação. Câmara de Educação Superior. Resolução CNE / CES N 3 / 2005, de 23 junho de 2005. Institui as Diretrizes Curriculares Nacionais para o curso de graduação em Secretariado Executivo e dá outras Providências. Diário Oficial da União de 27 de junho de 2005, nº 121, p.79. Seção 1.

DEMO, Pedro. Desafios Modernos da Educação. 8 ed. Editora Vozes. Petrópolis, 1999.

DUTRA, Joel Souza. Competências: conceitos e instrumentos para a gestão de pessoas na empresa moderna. São Paulo: Atlas, 2004.

FLEURY, Maria Tereza Leme; FLEURY, Afonso. Construindo o conceito de competência. Rac. Edição Especial, p. 183-196, 2001.

KAUFMANN, Luiz. Passaporte para o ano 2000: como desenvolver e explorar a capacidade empreendedora para crescer com sucesso até o ano 2000. São Paulo: Makron: McGraw-Hill, 1990.

LE BOTERF, Guy. Desenvolvendo a competência dos profissionais. Tradução: REUILLARD, P. C. R. 3 ed. Porto Alegre: Artmed, 2003.

MARTINS, Ana Maria Santana. Profissão com novo perfil necessita de melhor formação. Revista da Fenassec Excelência, ano 4, nº. 11, p. 5, julho, agosto e setembro/2006. Trimestral.

MEDEIROS, João Bosco.; HERNANDES, Sonia. Manual da Secretária: código de ética profissional. 7. ed. São Paulo: Atlas, 1999. 
MENESES, Pedro Paulo Murce; ZERBINI Thaís. Levantamento de Necessidades de Treinamento: reflexões atuais. Revista de Administração da PUCRS. V. 20, n.2, p.50-64, julho/dezembro $2009 . \quad$ Disponível em> https://revistaseletronicas.pucrs.br/index.php/face/article/view/2644. Acesso em 13 set. 2021.

MILKOVICH, George T.; BOUDREAU, John W. Administração de Recursos Humanos. Tradução Reinaldo C. Marcondes. 8. ed. São Paulo: Atlas, 2000.

McCLELLAND, David C. Testing for Competence rather than Intelligence. American Psychologist, p. 1-14, jan. 1973

MUSSAK, Eugênio. Gestão Humanista de Pessoas: $O$ fator humano como diferencial competitivo. Rio de Janeiro. Elsevier, 2010.

NONAKA, Ikojiru. TAKEUCHI, Hirotaka. Criação do Conhecimento na empresa: como as empresas japonesas geram a dinâmica da inovação. 12. ed. Rio de Janeiro: Elsevier, 1997.

PIRES DE CARVALHO, Antonio.; GRISSON, Diller (Orgs.) Manual do Secretariado Executivo. 4. ed. São Paulo: D’Livros, 2001.

SEIFFERT, Peter Quadros. Empreendendo novos negócios em corporações: estratégias, processo e melhores práticas. 2. ed. São Paulo: Atlas, 2008.

SILVA, Ana Cristina Brandão Ribeiro. O Profissional Secretário Executivo: um estudo de caso exploratório sobre as competências que o mercado demanda dos profissionais formados pelas IES. Monografia de Pós-graduação em Gestão de Pessoas. Brasília, Faculdade. CECAP, 2007.

Os Desafios e Perspectivas da Gestão de Pessoas: conhecimentos, habilidades, atitudes. p.171-179. (Orgs) PORTELA, Keyla Christina Almeida; SCHUMACHER, Alexandre José. Gestão Secretarial: o desafio da visão holística. Volume I - Cuiabá: Adeptus, 2009.

Atuação e competências do secretário executivo: Assessor, Gestor, Consultor, Empreendedor. I Encontro Nacional Acadêmico de Secretariado Executivo, XII Encontro Regional de Secretariado Executivo, XXIII Semana Acadêmica de Secretariado Executivo. Anais. Biblioteca da Universidade Campus de Toledo/PR. ISSN:2179-1457. [CD-ROM], 2010.

SPENCER JR. L. M. e SPENCER, S. M. Competence at Work: Models for Superior Performance. Nova York: John Wiley, 1993.

ZARIFIAN, Philippe. Objetivo competência: por uma nova lógica. Tradução: Maria Helena C.V. Trylinski. São Paulo: Atlas, 2001.

ZORZI, Sonia Regina. Introdução. Secretária Assistente Executiva 2001. In: Pires de Carvalho, Antonio; Grisson, Diller (Orgs). Manual do Secretariado Executivo. 4 ed. São Paulo:D’Livros, 2001. 